\title{
Development of a High Temperature and High Pressure 0il-Based Drilling Fluid Emulsion Stability Tester
}

\author{
Huaiyuan Long1, Wu Chen'1, Dichen Tan', Lanping Yang², Shunyuan Zhang', Song Wang1* \\ ${ }^{1}$ Yangtze University, Jingzhou, China \\ ${ }^{2}$ China Petroleum Corporation Chuanqing Drilling Drilling Fluid Company, Chengdu, China \\ ${ }^{3}$ China Petroleum Corporation Engineering Technology Research Institute Co., Ltd., Beijing, China \\ Email: 332020105@qq.com, ${ }^{\star} 1508871707 @ q q . c o m$
}

How to cite this paper: Long, H.Y., Chen, W., Tan, D.C., Yang, L.P., Zhang, S.Y. and Wang, S. (2021) Development of a High Temperature and High Pressure Oil-Based Drilling Fluid Emulsion Stability Tester. Open Journal of Yangtze Gas and Oil, 6, 25-35.

https://doi.org/10.4236/ojogas.2021.62003

Received: January 12, 2021

Accepted: March 1, 2021

Published: March 4, 2021

Copyright (๑) 2021 by author(s) and Scientific Research Publishing Inc. This work is licensed under the Creative Commons Attribution International License (CC BY 4.0).

http://creativecommons.org/licenses/by/4.0/

\begin{abstract}
When drilling deep wells and ultra-deep wells, the downhole high temperature and high pressure environment will affect the emulsion stability of oil-based drilling fluids. Moreover, neither the demulsification voltage method nor the centrifugal method currently used to evaluate the stability of oil-based drilling fluids can reflect the emulsification stability of drilling fluids under high temperature and high pressure on site. Therefore, a high-temperature and high-pressure oil-based drilling fluid emulsion stability evaluation instrument is studied, which is mainly composed of a high-temperature autoclave body, a test electrode, a temperature control system, a pressure control system, and a test system. The stability test results of the instrument show that the instrument can achieve stable testing and the test data has high reliability. This instrument is used to analyze the factors affecting the emulsion stability of oil-based drilling fluids. The experimental results show that under the same conditions, the higher the stirring speed, the better the emulsion stability of the drilling fluid; the longer the stirring time, the better the emulsion stability of the drilling fluid; the greater the oil-water ratio, the better the emulsion stability of the drilling fluid. And the test results of the emulsification stability of oil-based drilling fluids at high temperature and high pressure show that under the same pressure, as the temperature rises, the emulsion stability of oil-based drilling fluids is significantly reduced; at the same temperature, the With the increase in pressure, the emulsion stability of oil-based drilling fluids is in a downward trend, but the decline is not large. Relatively speaking, the influence of temperature on the emulsion stability of oil-based drilling fluids is greater than that of pressure.
\end{abstract}




\section{Keywords}

Oil-Based Drilling Fluid, Emulsification, Demulsification Voltage, Tester, High Temperature and High Pressure

\section{Introduction}

With the continuous development of international petroleum exploration and development technologies, the deeper and deeper the well is, the more difficult it is to explore and develop oil and gas. Oil-based drilling fluid is a dispersion system with water droplets as the dispersed phase and oil (diesel or mineral oil) as the continuous phase. A certain amount of emulsifier, lipophilic colloid, weighting agent and other treatment agents are added during the preparation process. The formation of a stable emulsion system. The emulsion stability of oil-based drilling fluids directly affects the performance of the drilling fluid, which is one of the core issues of drilling fluid research. When drilling deep wells and ultra-deep wells, the downhole high temperature and high pressure environment will destroy the performance of the drilling fluid, thereby affecting the emulsion stability of the drilling fluid. Therefore, it is very important to develop an oil-based drilling fluid emulsion stability tester under high temperature and high pressure conditions and establish an evaluation method [1]-[6].

\section{Design Scheme of Emulsification Stability Tester}

As shown in Figure 1, the high-temperature and high-pressure oil-based drilling fluid emulsion stability tester is mainly composed of a high-temperature autoclave body, a test electrode, a temperature control system, a pressure control system, and a test system.

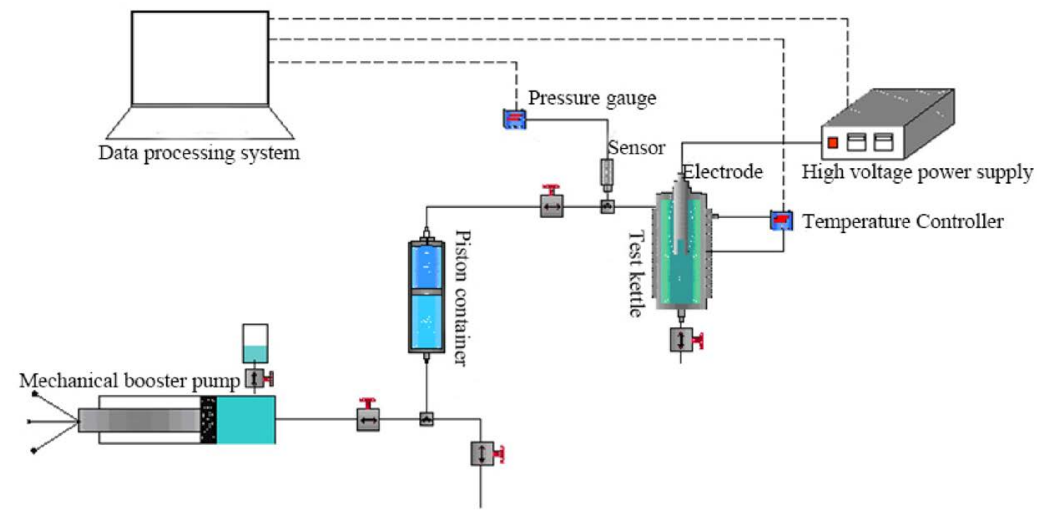

Figure 1. Schematic diagram of the composition of the high temperature and high pressure oil-based drilling fluid emulsion stability tester.

\subsection{Temperature Control System}

The system uses cast aluminum electric heaters for heating, and the electric heaters are wrapped outside the test kettle body to maintain a constant temperature 
required for experimental testing. This system is based on the T89C51 single-chip microcomputer as the core, composed of a temperature control integrated system that integrates temperature data acquisition, data storage, signal conversion, and intelligent control of the high temperature and high pressure oil-based drilling fluid emulsion stability evaluation device [7] [8] [9] [10], Its principle block diagram is shown in Figure 2.

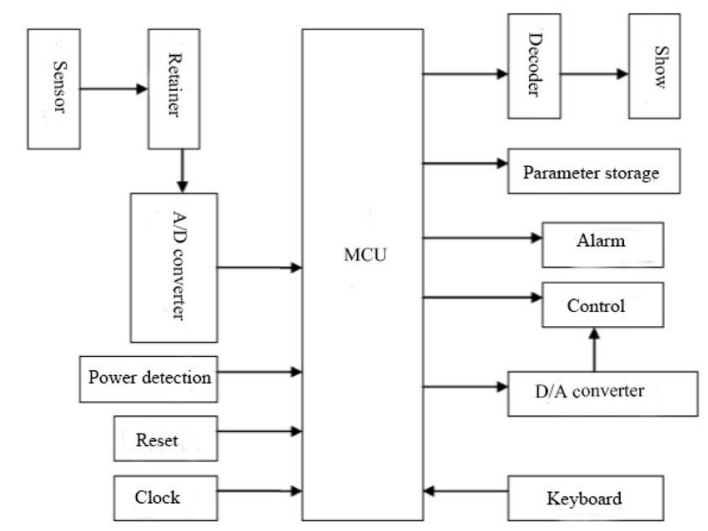

Figure 2. Block diagram of temperature control system.

The technical indicators of the heating system are as follows:

1) Power source: $220 \mathrm{~V} \pm 10 \mathrm{~V} 50 \mathrm{~Hz}$;

2) Temperature control range: room temperature $\sim 200^{\circ} \mathrm{C}$;

3) Temperature control accuracy: $\leq \pm 1^{\circ} \mathrm{C}$.

\subsection{Pressurized System}

The pressurizing system is mainly composed of a mechanical booster pump and a piston container.

1) Mechanical booster pump

The pump is a screw plunger pump with a gear assist system, and the pump cavity is made of $316 \mathrm{~L}$ stainless steel.

2) Piston container

The piston container used in this instrument is equipped with an isolation piston, and the piston is sealed and isolated by O-ring and Y-ring. The design drawing of the piston container is shown in Figure 3.

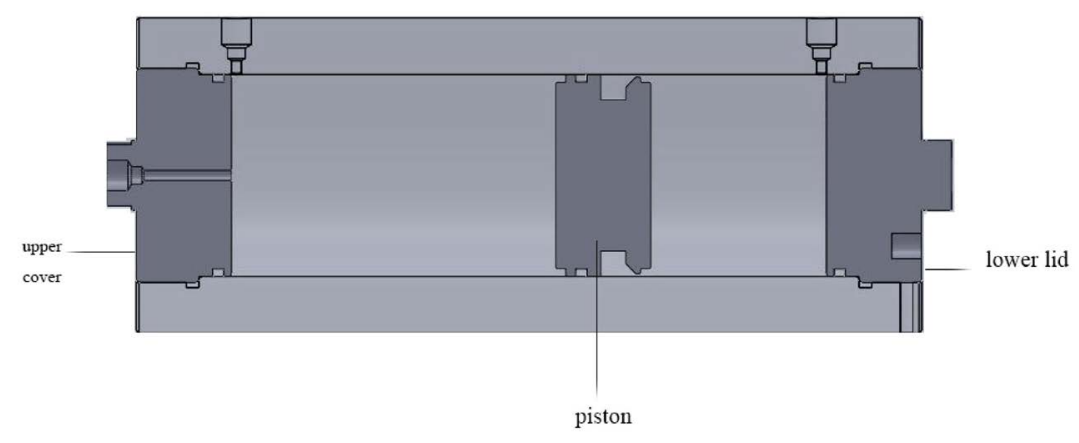

Figure 3. Piston container. 


\subsection{Test Kettle Body and Test Electrode}

The test kettle body is composed of a kettle body and an upper cover. It is made of $316 \mathrm{~L}$ material. There is a through hole in the middle of the upper cover. The through hole is used to install the test electrode. The test electrode is made of PEEK material. The electrode plate is embedded in the PEEK test head. At the lower end, the distance between the two electrodes is $1.5 \mathrm{~mm}$, with an error of $\pm 0.05 \mathrm{~mm}$. The power cord of the electrode passes through the inside of the PEEK test head, and an O-ring is used to seal the gap between the PEEK test head and the top cover of the kettle. Design a special gland, the special gland is connected with the upper cover of the high temperature and high pressure stainless steel cavity with precision threaded connection, which is used to compress the PEEK test head to prevent the test head from spraying out under high pressure. The schematic diagram of the test kettle and electrode is shown in Figure 4 .

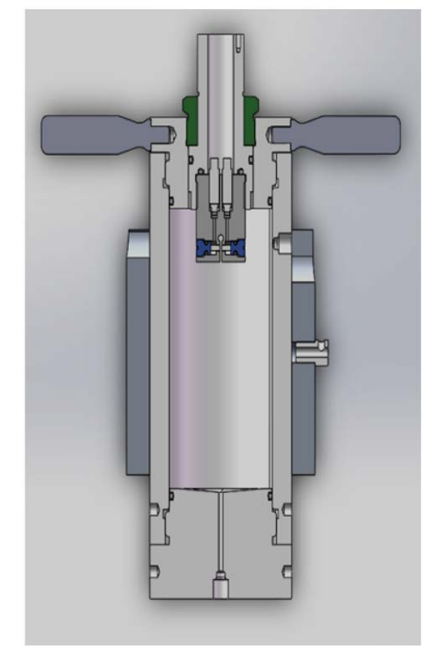

Figure 4. Test kettle and electrode.

\subsection{Test System}

The measurement system consists of pressure measurement, temperature measurement and voltage measurement.

1) Pressure measurement

It is mainly used to measure the pressure in the sample cup during the demulsification experiment. It is measured by a high-precision pressure sensor. The range is: 0 - $15 \mathrm{MPa}$, and the accuracy is $0.1 \%$ F.S.

2) Temperature measurement

Mainly measure the temperature in the high temperature and high pressure stainless steel cavity, using PT100 temperature sensor, its range is: $0^{\circ} \mathrm{C}-400^{\circ} \mathrm{C}$, measurement error: $\pm 0.1^{\circ} \mathrm{C}$, measurement accuracy, $0.2 \%$ F.S.

3) Demulsification voltage measurement

The demulsification voltage is automatically loaded by a dedicated power supply for measurement, and the measured value is displayed digitally, which is 
intuitive and easy to read.

Demulsification voltage range: 0 - 2000 V; error: $\leq 5 \%$.

\subsection{Data Acquisition System}

The computer dynamically collects the pressure, temperature, demulsification voltage and other parameters in the process of the emulsion stability experiment of the high temperature and high pressure oil-based drilling fluid to meet the process monitoring and data collection and storage of the experiment process.

In order to ensure the accuracy of acquisition and the stability of the electrical system, the following measures have been taken:

1) All analog input and output signals enter the electrical system through the isolation safety barrier. The anti-interference ability of the data acquisition system is enhanced to ensure the stability, reliability and accuracy of the test data.

2) Take effective measures to suppress electromagnetic radiation. Ensure that the electromagnetic field intensity at a distance of $30 \mathrm{~cm}$ from the control cabinet is less than $0.2 \mu \mathrm{T}$, and the electromagnetic radiation intensity is less than 40 $\mu \mathrm{W} / \mathrm{cm}^{2}$, which are all lower than the safety limit in the national standard.

3) Take effective measures to improve the electrical system's ability to resist electrical transient fast pulse groups and surges to ensure that the system can work normally under lightning strikes and current disturbances.

4) Take effective measures to improve the ability of the electrical system to resist voltage drops. Ensure that the system can work normally when the grid voltage fluctuates.

\subsection{The Main Technical Parameters of the Instrument}

Demulsification voltage: 0 - $2000 \mathrm{~V}$; voltage change rate: $150 \pm 10 \mathrm{~V}$ per second, automatic operation; working temperature: $0^{\circ} \mathrm{C}-200^{\circ} \mathrm{C}$; working pressure: 10 $\mathrm{MPa}$; kettle volume: $1000 \mathrm{ml}$; working power supply: AC $220 \mathrm{~V}$; electrode spacing: $1.55 \pm 0.04 \mathrm{~mm}$; working time: $24 \mathrm{~h}$ continuous work; rated power: $1500 \mathrm{~W}$.

\section{Parallelism Study of Emulsion Stability Tester}

The parallelism of the instrument is an important indicator of its performance. For this reason, the three samples were tested 20 times under the same conditions. The results are shown in Figure 5. The data of 20 parallel experiments of the same experimental fluid show that the parallelism of the test data is good. The demulsification voltage of 1 \# test solution is concentrated between $200 \mathrm{~V}$ and $221 \mathrm{~V}$, the demulsification voltage of $2 \#$ test solution is concentrated between $620 \mathrm{~V}$ and $680 \mathrm{~V}$, and the demulsification voltage of 3\# test solution is concentrated between $912 \mathrm{~V}$ and $996 \mathrm{~V}$. Through the statistical analysis of the above data, it can be determined that the demulsification voltage value of the test solution fluctuates around $\pm 4 \%$, indicating that the instrument has good parallelism and reliable data, which can meet the requirements of experimental design. 


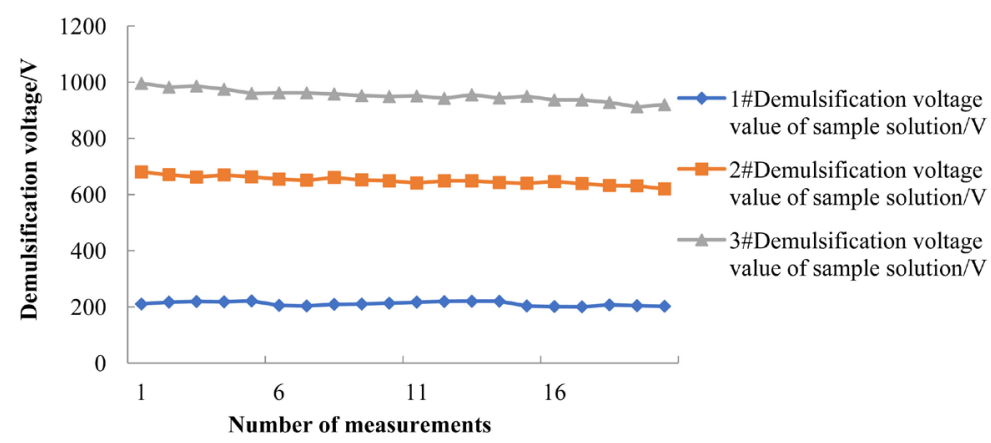

Figure 5. Schematic diagram of 20 repeated test results of demulsification voltage of different sample solutions.

\section{Influencing Factors of Oil-Based Drilling Fluid Emulsion Stability}

An oil-based drilling fluid is prepared indoors. Its basic composition is as follows, changing different oil-water ratios $+3 \%$ emulsifier $+2 \%$ fluid loss additive $+3 \%$ organic soil $+2 \% \mathrm{CaO}+$ oil-wetting barite (adjusting density). The above-developed instruments are used to determine the factors affecting the emulsion stability of oil-based drilling fluids.

\subsection{Stirring Speed}

Prepare $500 \mathrm{ml}$ water-in-oil emulsion with an oil-water ratio of 90:10. The stirring speeds are $4000 \mathrm{r} / \mathrm{min}, 6000 \mathrm{r} / \mathrm{min}, 8000 \mathrm{r} / \mathrm{min}, 10,000 \mathrm{r} / \mathrm{min}, 12,000 \mathrm{r} / \mathrm{min}$, and the stirring time is $20 \mathrm{~min}$. Test the demulsification voltage under different stirring speeds, and the results are shown in Figure 6.

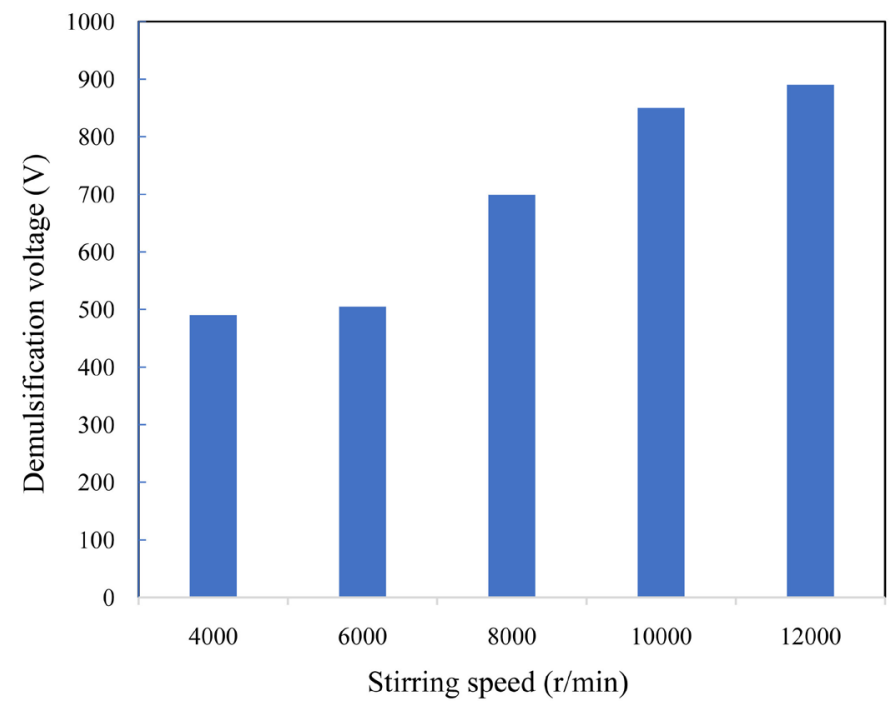

Figure 6. The effect of stirring speed on demulsification voltage.

It can be seen from the test results that the stirring speed is $12,000 \mathrm{r} / \mathrm{min}$, the dispersed particles of water droplets are the smallest, the emulsion breaking voltage is the largest, and the stability of the emulsion is the best. 


\subsection{Stirring Time}

Prepare $500 \mathrm{ml}$ of water-in-oil emulsion with oil-water ratio of 90:10, stirring speed of 12,000 r/min, stirring time of $20 \mathrm{~min}, 40 \mathrm{~min}$, and $60 \mathrm{~min}$ respectively, and measure the demulsification voltage under different stirring time. The results are shown in Figure 7 shown.

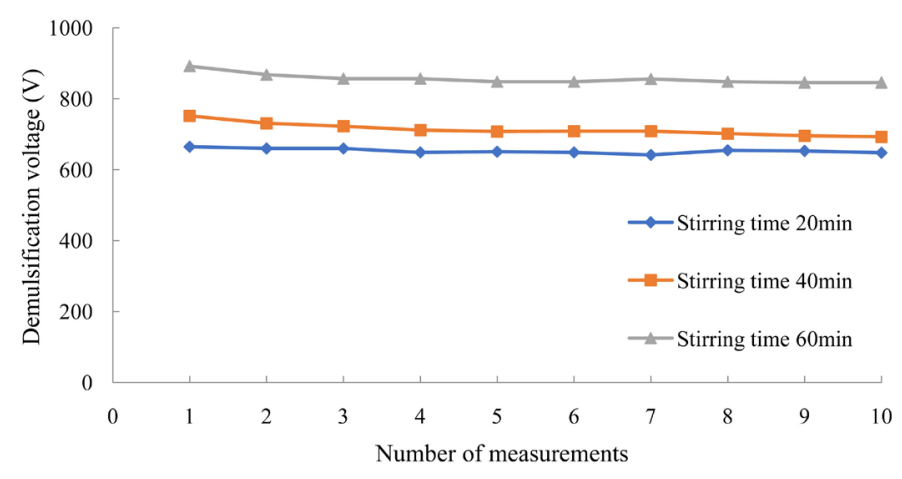

Figure 7. Effect of stirring time on demulsification voltage.

From the test results, it can be seen that the demulsification voltage value of the emulsion obtained with a stirring time of 60 minutes is the largest. This is because the longer the stirring time, the better the dispersion of the aqueous phase, which shows that the demulsification voltage is greater and the stability of the emulsion better.

\subsection{Oil-Water Ratio}

Under the premise of the same stirring time, stirring speed and other conditions, change the oil-water ratio of the emulsion to prepare four groups of water-in-oil emulsions with oil-water ratios of 60:40, 70:30, 80:20, and 90:10. The test results are shown in Figure 8.

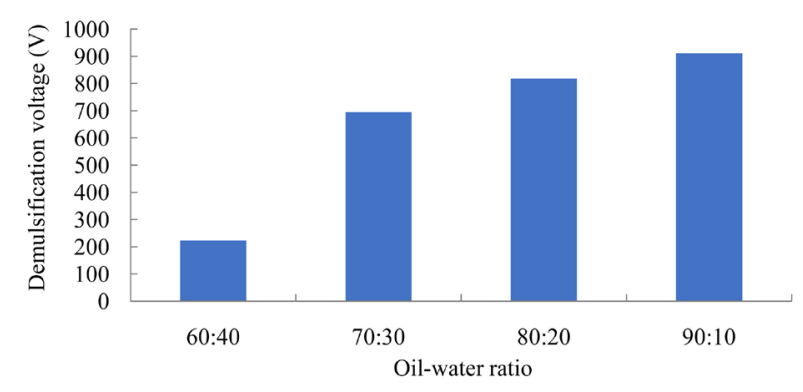

Figure 8. The effect of oil-water ratio on demulsification voltage.

\subsection{Type and Amount of Emulsifier}

Prepare $500 \mathrm{ml}$ water-in-oil emulsion with oil-water ratio of 90:10, stirring speed is $12,000 \mathrm{r} / \mathrm{min}$, stirring time is $60 \mathrm{~min}$. Three different emulsifiers produced by Hubei Haoren Petroleum Technology Co., Ltd. were used to prepare emulsions, and the demulsification voltage of each emulsion was tested. The experimental data is shown in Table 1. 
Table 1. Demulsification voltage value under different emulsifier and dosage.

\begin{tabular}{cccc}
\hline Type of emulsifier & Emulsifier I & Emulsifier II & Emulsifier III \\
\cline { 1 - 3 } Emulsifier dosage & & & \\
\hline $2 \%$ & 428 & 512 & 740 \\
$3 \%$ & 495 & 680 & 880 \\
$4 \%$ & 567 & 728 & 987 \\
\hline
\end{tabular}

From the above data, it can be seen that with the increase of emulsifier dosage, the demulsification voltage of emulsifier I and emulsifier III increases, and the demulsification voltage reaches the maximum when the dosage of emulsifier II is $3 \%$. When the addition amount of emulsifier III is $4 \%$, the demulsification voltage value of the prepared emulsion is the largest, and the stability of the emulsion is the best.

\section{Evaluation of Emulsion Stability of High Temperature and High Pressure Oil-Based Drilling Fluid Emulsion}

The developed tester was used to evaluate the emulsion stability of high temperature and high pressure oil-based drilling fluid emulsion.

\subsection{The Influence of Temperature on the Emulsification Stability of Water-in-Oil Emulsions}

The experiment was carried out under the same pressure, and the effects of different temperatures on the demulsification voltage of oil-based drilling fluid were tested. Equipped with $1000 \mathrm{ml}$ of oil-based drilling fluid, the experimental formula is: oil-water ratio $90: 10\left(25 \% \mathrm{CaCl}_{2}\right.$ solution $)+3 \% \mathrm{RHJ}-\mathrm{I}$ primary emulsifier $+1.5 \%$ RHJ-2 auxiliary emulsifier $+3 \%$ JLS-2 fluid loss additive $+3 \%$ organic soil $+2 \% \mathrm{CaO}+$ oil wetting barite. Test the demulsification voltage corresponding to different temperatures under the same pressure, and the experimental data is shown in Figure 9. When the pressure is kept constant, with the increase of temperature, the demulsification voltage value shows a downward trend, indicating that the emulsion stability of oil-based drilling fluid decreases with the increase of temperature [11] [12] [13] [14] [15].

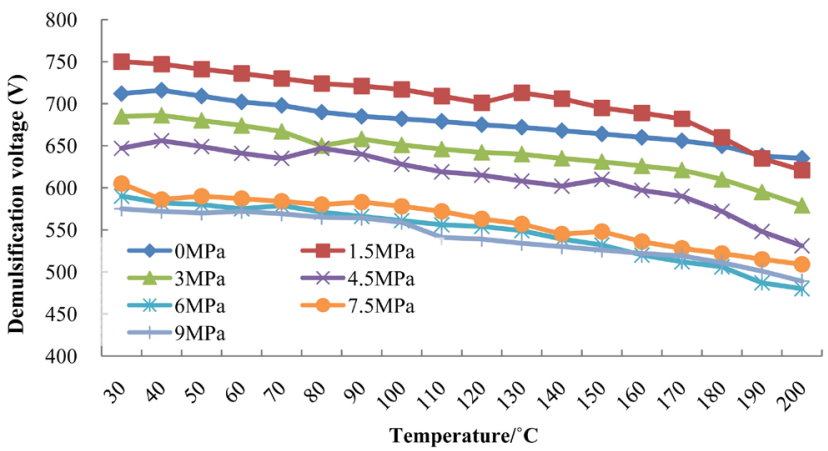

Figure 9. The influence of temperature on the emulsion stability of 90:10 oil-water ratio emulsion. 


\subsection{The Influence of Pressure on the Emulsification Stability of Water-in-0il Emulsions}

Equipped with $1000 \mathrm{ml}$ of oil-based drilling fluid, the experimental formula is: oil-water ratio 90:10 (25\% $\mathrm{CaCl}_{2}$ solution $)+3 \% \mathrm{RHJ}$-I primary emulsifier + $1.5 \% \mathrm{RHJ}-2$ auxiliary emulsifier $+3 \%$ JLS- 2 fluid loss additive $+3 \%$ organic soil $+2 \% \mathrm{CaO}+$ oil wetting barite. Test the demulsification voltage values corresponding to different temperatures under different pressures, and the experimental data is shown in Figure 10.

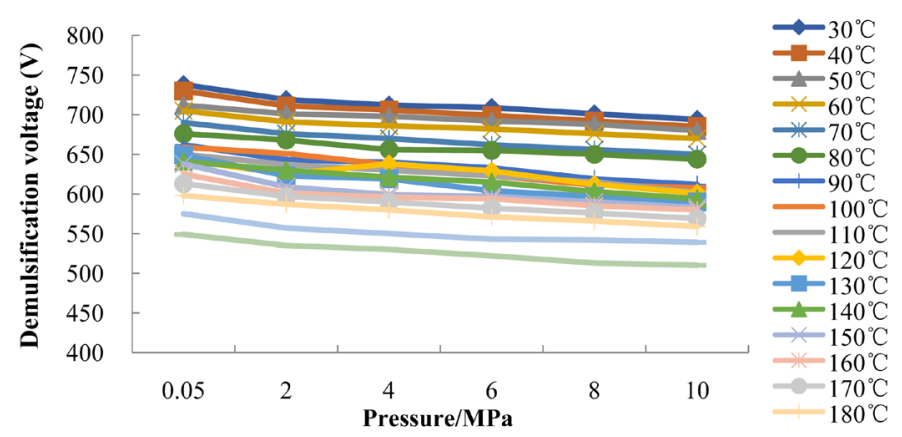

Figure 10. The effect of pressure on the emulsion stability of an oil-water ratio of 90:10.

It can be seen from Figure 10 that when the temperature is lower than $120^{\circ} \mathrm{C}$, as the pressure increases, the demulsification voltage decreases, indicating that the emulsion stability of the drilling fluid decreases as the pressure increases. When the temperature reaches above $120^{\circ} \mathrm{C}$, the demulsification voltage of the emulsion basically does not change with the change of pressure, indicating that the pressure has little effect on the emulsion stability of the drilling fluid in a high temperature and high pressure environment, and the temperature affects it. Leading role.

\section{Conclusion and Understanding}

1) High temperature and high pressure oil-based drilling fluid emulsion stability evaluation instrument is mainly composed of high temperature and high pressure kettle body, test electrode, temperature control system, pressure control system and test system.

2) Tests on the safety performance of the instrument and the repeatability of the test data. The experimental results show that the instrument has good performance and the test results are accurate and reliable, which can meet the overall requirements of the instrument design.

3) The analysis of factors affecting the emulsion stability of oil-based drilling fluids by this instrument shows that under the same conditions, the higher the stirring speed, the better the emulsion stability; the longer the stirring time, the better the emulsion stability; The greater the oil-water ratio, the better the emulsion stability of the emulsion.

4) The test of emulsification stability of oil-based drilling fluid under high temperature and high pressure by this instrument shows that under the same 
pressure, with the increase of temperature, the emulsification stability of oil-based drilling fluid is obviously reduced; under the same temperature, with the increase of pressure, the emulsion stability of oil-based drilling fluids is in a downward trend, but the decline is not large. Relatively speaking, the influence of temperature on the emulsion stability of oil-based drilling fluids is greater than that of pressure.

\section{Fund Project}

National Science and Technology Major Project (2016ZX05033).

\section{Conflicts of Interest}

The authors declare no conflicts of interest regarding the publication of this paper.

\section{References}

[1] Ma, B.D., Gao, B.Y., Lu, L., et al. (2010) Stability Experiment of Binary Composite System Oil-Water Emulsion. Oil and Gas Field Surface Engineering, 29, 10-12.

[2] Zhang, F.G., Zhao, J.X., Jiang, J.X., et al. (2007) Quick Evaluation of O/W Emulsion Stability by Centrifugation-Electrical Lead Usage. Applied Chemistry, No. 8, 43-48.

[3] Fan, Z.X., Guo, X.Q., Wang, J.X., et al. (2007) Research on the Optical Evaluation Method of Crude Oil Emulsion Stability. Journal of China University of Petroleum (Natural Science Edition), No. 4, 38-41.

[4] Yu, H.X., Lin, L. and Liu, M. (2007) Experimental Study on the Stability of Heavy Oil Emulsion. Oil and Gas Field Surface Engineering, No. 10, 45-49.

[5] Li, C.X., Huang, J.J. and Xu, Y. (2002) A New Type of High Temperature Stable Oil-Based Drilling Fluid Wetting Reversal Agent. Journal of Southwest Petroleum Institute, No. 5, 78-82.

[6] Yu, X.D., Yao, X.Z., Lin, S.N., et al. (2001) Research and Application of Anti-220 ${ }^{\circ} \mathrm{C}$ High Temperature Water-in-Oil Drilling Fluid. Petroleum Drilling Technology, No. 5, 58-63.

[7] Li, C.X., Huang, J.J., Gao, H.Y., et al. (2001) Development and Performance Evaluation of a New Type of High Temperature Resistant Organic Soil. Journal of Southwest Petroleum Institute, No. 4, 29-34.

[8] Xiong, B.T. (2012) Study on the Stability Mechanism of Oil-Based Drilling Fluid Emulsions. Yangtze University, Jinzhou.

[9] Xia, L.X., Cao, G.Y., Lu, S.X., et al. (2005) The Influence of Asphaltenes and Gums on the Stability of Emulsions. Chemical World, No. 9, 521-523.

[10] Liu, J.H. (2012) Study on the Stability and Demulsification Mechanism of Polymer Flooding Crude Oil Emulsion. China University of Petroleum, Beijing.

[11] Chen, Y.J., Zhang, Z.Q., Yuan, S.L., et al. (2003) Study on the Stability of Kerosene/Water Emulsion with Conductivity Method. Journal of Shandong University (Science Edition), No. 4, 62-65.

[12] Growcock, F.B. (2003) Application of Water-Based and Oil-Based Aphrons in Drilling Fluids. International Symposium on Oilfield Chemistry, Houston, February 2003, SPE-80208-MS. https://doi.org/10.2118/80208-MS

[13] Coutinho, R.C.C. (2011) Evaluation of Water-in-Crude-Oil Emulsion Stability Us- 
ing Critical Electric Field: Effect of Emulsion Preparation Procedure and Crude Oil Properties. Journal of Dispersion Science and Technology, 32, 923-934.

https://doi.org/10.1080/01932691.2010.488489

[14] Eow, J.S., Ghadiri, M. and Sharif, A. (2001) Deformation and Break-Up of Aqueous Drops in Dielectric Liquids in High Electric Fields. Journal of Electrostatics, 51, 463-469.

[15] Alistair, H., Stephen, V., Marcus, D., et al. (2009) Design and Application of Invert Emulsion Drilling and Aqueous Completion Fluids for Long Horizontal Multilateral Wells. The 8th European Formation Damage Conference, Scheveningen, May 2009, SPE-121905-MS. https://doi.org/10.2118/121905-MS 